\title{
Anatomical features of the occipital artery on CTA and differences between patients with/without stenosis and occlusion of the internal carotid artery
}

\author{
TENGFEI LUAN and JINLU YU \\ Department of Neurosurgery, The First Hospital of Jilin University, Changchun, Jilin 130021, P.R. China
}

Received October 13, 2021; Accepted December 28, 2021

DOI: $10.3892 / \mathrm{mi} .2021 .28$

\begin{abstract}
The understanding of the basic anatomy of the occipital artery (OA) is crucial, and computed tomography angiography is an effective tool for this purpose. In the present study, a comparison between healthy subjects and patients with internal carotid artery (ICA) stenosis and occlusion was made. The following parameters were measured: Age, sex, diameters and lengths of the OA in different locations, distance from the edge of the foramen magnum to the OA and the distance from the midline to the OA at the level of the superior nuchal line. A total of 205 participants who met the inclusion criteria were selected for further investigation. In addition, 50 healthy subjects (100 sides, left and/or right) were selected as the control group. A total of 155 patients (180 sides, left and/or right) were selected as the stenosis and occlusion groups, including the mild and moderate ICA stenosis group (50 sides, left and/or right), severe ICA stenosis group (80 sides, left and/or right) and the ICA occlusion group (50 sides, left and right). General information, measured parameters and statistical analysis results are provided for these groups. No significant differences were observed in the anatomical parameters of the OA among these groups. Thus, in addition to providing anatomical data, the present study demonstrates that stenosis and the occlusion of the ICA do not significantly alter the anatomy of the OA.
\end{abstract}

\section{Introduction}

The occipital artery (OA) is a main artery that originates from the external carotid artery (ECA) and may be involved in a number of diseases, such as moyamoya disease, dural

Correspondence to: Dr Jinlu Yu, Department of Neurosurgery, The First Hospital of Jilin University, 1 Xinmin Avenue, Changchun, Jilin 130021, P.R. China

E-mail: jlyu@jlu.edu.cn; jinluyu@hotmail.com

Abbreviations: CTA, computed tomography angiography; ECA, external carotid artery; ICA, internal carotid artery; OA, occipital artery

Key words: computed tomography angiography, occipital artery, internal carotid artery, stenosis, occlusion arteriovenous fistula (DAVF), aneurysm, etc. (1). Apart from its involvement in these diseases, the OA is a crucial artery due to its main anatomical variations and its usage in intraand extracranial bypasses; therefore, the understanding of the anatomy of the OA is of utmost importance (2).

Previous studies on the OA have been mostly based on cadavers and catheter-based angiography procedures (3-5). Studies using computed tomography angiography (CTA) are rarely reported $(6,7)$. Therefore, the present study was performed to examine the anatomy of the OA using CTA. Importantly, the data of the present study were derived from Han Chinese subjects, a population cohort that has rarely been reported in such cases.

In addition to providing OA parameters, most importantly, in the present study, the OA anatomy was compared between healthy subjects and patients with internal carotid artery (ICA) stenosis and occlusion to determine whether the OA parameters differed. This was performed as the OA can become dilated or thicker than normal in the presence of a DAVF (1). To date, no study has explored this issue, at least to the best of our knowledge.

\section{Materials and methods}

Study participants. An imaging study was performed on Han Chinese candidates, including healthy subjects and patients with ICA stenosis and occlusion, who underwent cervical CTA examinations between January, 2020 and September, 2021 at the First Hospital of Jilin University, Changchun, China. The healthy subjects underwent a cervical CTA examination during routine physical examinations.

Prior to the CTA, the following exclusion criteria were used: A history of severe or anaphylactic reaction to iodinated contrast, an inability to cooperate with scanning protocols, hemodynamic instability, diabetes, the administration of any anticoagulant medication, renal impairment.

The present study was approved by the Ethics Committee of the First Hospital of Jilin University (approval no. 2021-533). Written informed consent was obtained from all participants. The original CTA data were further processed on a GE Workstation (version 4.7) (GE Healthcare; Cytiva).

CTA imaging protocol. CTA examinations were performed on 256-multidetector CT scanners (GE Healthcare; Cytiva) at 

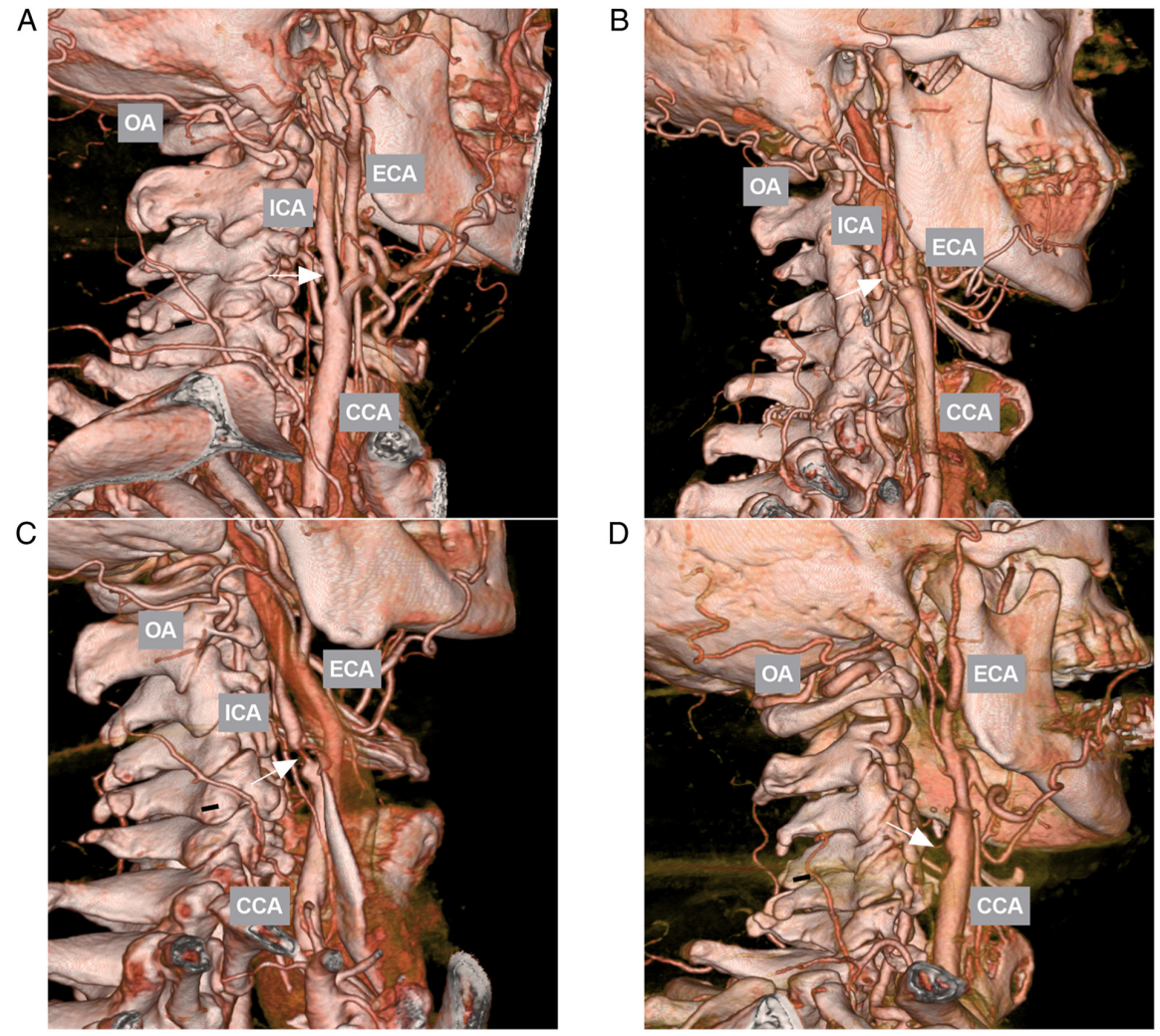

Figure 1. CTA of the ICA in different groups. (A) CTA illustrating mild ICA stenosis (arrow). (B) CTA illustrating moderate ICA stenosis (arrow). (C) CTA illustrating severe ICA stenosis (arrow). (D) CTA illustrating an ICA occlusion (arrow). CCA, common carotid artery; CTA, computed tomography angiography; ECA, external carotid artery; ICA, internal carotid artery; OA, occipital artery.

the First Hospital of Jilin University, utilizing THE test bolus injection technique to acquire the optimal trigger time (8). The scanned area ranged from the aortic arch to the frontal sinus. On the basis of the body weight of the patient, a dose of $2 \mathrm{ml} / \mathrm{kg}$ of nonionic iodinated contrast media (Omnipaque 350; GE Healthcare; Cytiva) and 20-30 ml saline chaser were injected via an antecubital vein through an 18-gauge peripheral intravenous line at a flow rate of 4 to $5 \mathrm{ml} / \mathrm{sec}$ using a MedRad Mark V power injector (MedRad, Inc.) (9).

Inclusion criteria and grouping. First, contrast-enhanced imaging upon CTA of the participants was clear, and the ECA and OA could be clearly seen and measured. For the healthy subjects, no ECA or ICA abnormities were observed. For patients with ICA stenosis and occlusion, the history of ICA stenosis and occlusion was chronic and progressive due to arteriosclerosis; in these patients, the ECA was normal and had no stenosis at the origin. No tumor or vascular diseases, such as scalp or intramuscular hemangioma $(10,11)$, arteriovenous malformation (12), or DAVF (13), were associated with the OA.

Accordingly, the patients were divided into a mild and moderate ICA stenosis (ICA stenosis $<70 \%$ ) group, a severe ICA stenosis (ICA stenosis 70-99\%) group and an ICA occlusion group (Fig. 1) (14).

Software and tools used for post-processing. The raw CTA data were post-processed using the GE Workstation (version 4.7; GE Healthcare; Cytiva). The raw CTA data were primarily reconstructed using volume rendering.
Structures that affected the measurements were removed using the cutting tool. The diameter of the vessel and the distances between structures were obtained using the 'measure distance' tool. The curved length of a vessel was measured using the two-click AVA tool, and the curved three-dimensional length could be measured accurately. All the parameters were measured three times, and the average value was used for analysis.

\section{Measured parameters}

Vessel diameter. The vessel diameters included the ECA diameter at the OA origin, the OA diameter at its origin, the OA diameter at the superior nuchal line, the OA diameter $2 \mathrm{~cm}$ above the superior nuchal line and the OA diameter at the midline of the foramen magnum. When measuring the OA diameter at the superior nuchal line and OA diameter $2 \mathrm{~cm}$ above the superior nuchal line, if the OA was branched, the thickest portion of the main trunk was measured.

Curve length of the vessel. The curve lengths included the lengths of the OA from its origin to the superior nuchal line, between the superior nuchal line and $2 \mathrm{~cm}$ above the superior nuchal line, and from the midline level of the foramen magnum to the superior nuchal line. When measuring these parameters, if the OA was branched, the thickest portion of the main trunk was measured.

Spatial distance. The spatial distances included the distance from the edge of the foramen magnum to the OA and the distance from the midline to the OA at the level of the superior nuchal line. For the distance from the midline to the OA at the level of the superior nuchal line, if the OA was 

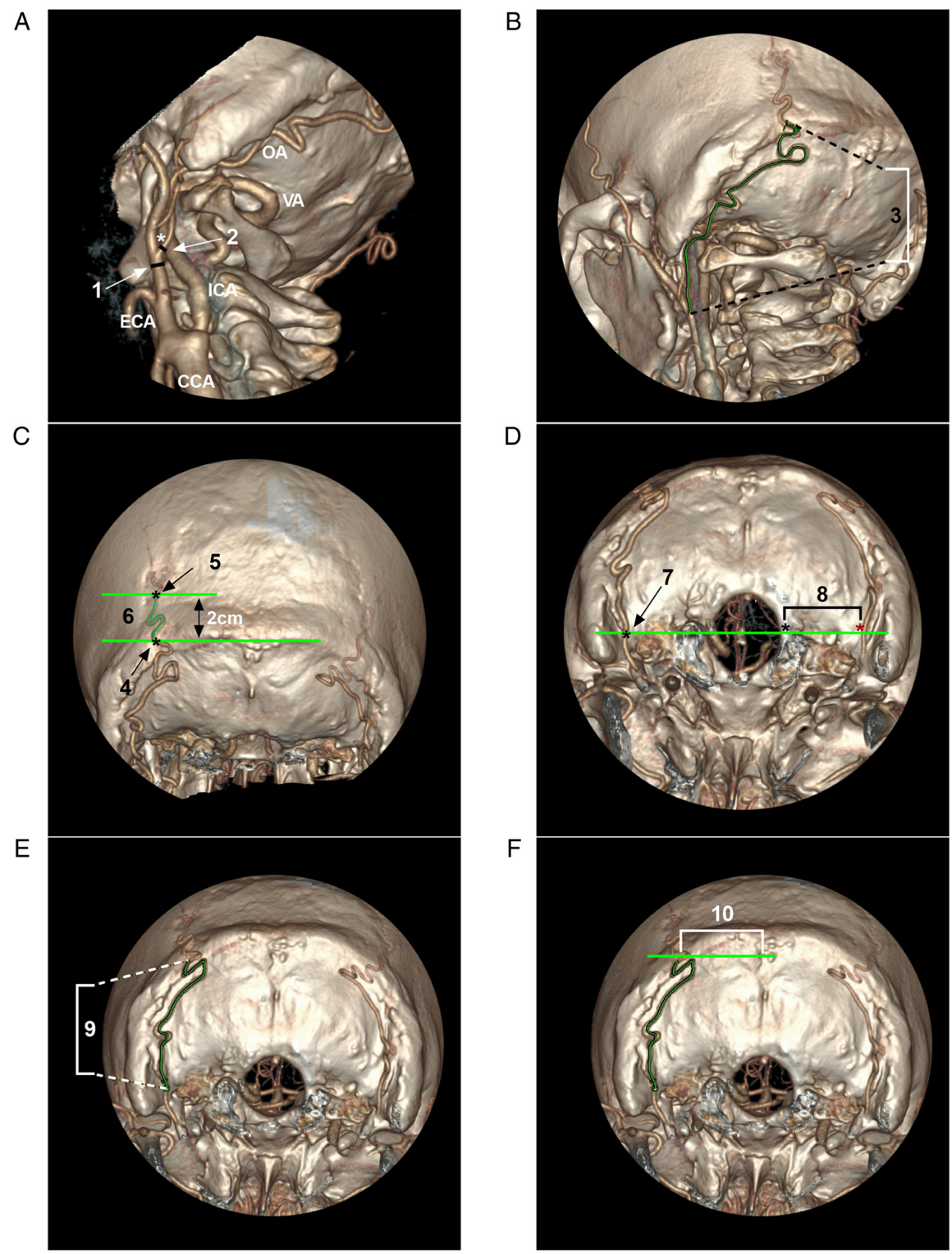

Figure 2. Parameters measured on computed tomography angiography. (A) The number 1 indicates the diameter of the ECA at the OA origin, and the number 2 indicates the diameter of the $\mathrm{OA}$ at its origin. (B) Number 3 indicates the length of the OA from its origin to the superior nuchal line. (C) Number 4 indicates the diameter of the OA at the middle of the superior nuchal line, number 5 indicates the diameter of the OA $2 \mathrm{~cm}$ above the middle of the superior nuchal line, and number 6 indicates the length of the OA between the superior nuchal line and $2 \mathrm{~cm}$ above the superior nuchal line. (D) Number 7 indicates the OA diameter at the midline of the foramen magnum, and number 8 indicates the distance from the edge of the foramen magnum to the OA. (E) Number 9 indicates the length of the OA from the midline level of the foramen magnum to the superior nuchal line. (F) Number 10 indicates the distance from the midline to the OA at the level of the superior nuchal line. CCA, common carotid artery; ECA, external carotid artery; ICA, internal carotid artery; OA, occipital artery; VA, vertebral artery.

branched, the thickest portion of the main trunk was measured. All measured parameters are illustrated in Fig. 2.

$O A$ variations. A number of variations were recorded, including the common origin with other ECA branches arising from the ICA and OA-vertebral artery anastomosis (Fig. 3).

Statistical analysis. Statistical assessments were performed using GraphPad Prism (version 8.02) software (GraphPad Software, Inc.). Continuous variables are expressed as the mean \pm standard deviation. A paired t-test was used for the comparison of two continuous variables. Ordinary one-way ANOVA followed by Tukey's multiple comparisons test was used for the comparison of multiple continuous variables.
The Chi-squared test was used to compare count data among multiple groups. A P-value $<0.05$ was considered to indicate a statistically significant difference.

\section{Results}

General information. A total of 205 Han Chinese participants who met the inclusion criteria were selected for further investigation. A total of 50 healthy subjects (100 sides, left and/or right) were selected as the control group. In total, 155 patients (180 sides) were selected as the stenosis and occlusion groups, including the mild and moderate ICA stenosis group (50 sides, left and/or right), severe ICA stenosis group (80 sides, left and/or right) and ICA occlusion group (50 sides, left and/or right). 
Table I. Age data of the study participants.

\begin{tabular}{lcc}
\hline Group & Range (years) & Mean (years) $^{\text {P-value }^{\mathrm{a}}}$ \\
\hline Control (50 subjects) & $33-88$ & $60.14 \pm 11.56$ \\
Mild and moderate ICA stenosis (38 subjects) & $37-80$ & $64.26 \pm 9.38$ \\
Severe ICA stenosis (71 subjects) & $33-79$ & $64.73 \pm 8.31$ \\
ICA occlusion (46 subjects) & $41-80$ & $62.04 \pm 9.36$
\end{tabular}

aThe data were analyzed using ordinary one-way ANOVA; due to the P-value $>0.05$, one-way ANOVA indicated that the degree of ICA stenosis had no significant effect on patient age. The P-values from multiple comparisons between groups are presented in Table III. ICA, internal carotid artery.

Table II. Sex data of the study participants.

\begin{tabular}{lccc}
\hline Group & Male (no. of participants) & Female (no. of participants) & P-value \\
\hline Control (50 subjects) & 33 & 17 & 0.5947 \\
Mild and moderate ICA stenosis (38 subjects) & 28 & 10 \\
Severe ICA stenosis (71 subjects) & 43 & 28 \\
ICA occlusion (46 subjects) & 30 & 16 \\
\hline
\end{tabular}

${ }^{a}$ Data were analyzed using the Chi-squared test; due to the P-value $>0.05$, the Chi-squared test indicated that the degree of ICA stenosis had no significant effect on the sex of patients. P-values of all the comparisons made are presented in Table III. ICA, internal carotid artery.

Table III. Multiple comparisons of the age and sex data in Tables I and II.

\begin{tabular}{lrr}
\hline & & \multicolumn{1}{c}{ P-value } \\
\cline { 2 - 3 } Comparison between groups & Age & Sex \\
\hline Control vs. mild and moderate ICA stenosis & 0.1942 & 0.4388 \\
Control vs. severe ICA stenosis group & 0.0505 & 0.5423 \\
Control vs. ICA occlusion group & 0.7672 & 0.9357 \\
Mild and moderate ICA stenosis vs. severe ICA stenosis group & 0.9950 & 0.1707 \\
Mild and moderate ICA stenosis vs. ICA occlusion group & 0.7184 & 0.4035 \\
Severe ICA stenosis group vs. ICA occlusion group & 0.4530 & 0.6117 \\
\hline
\end{tabular}

For age data, Tukey's multiple comparisons test was used. For sex data, the Chi-squared test was used. ICA, internal carotid artery.

In the control group (50 subjects), the average age was $60.14 \pm 11.56$ years (range, $33-88$ years), and the ratio of males to females was $1.94: 1(33 / 17)$. In the mild and moderate ICA stenosis group (38 patients), the average age was $64.26 \pm 9.38$ years (range, $37-80$ ), and the ratio of males to females was 2.8:1 (28/10). In the severe ICA stenosis group (71 patients), the average age was $64.73 \pm 8.31$ years (range, 33-79 years), and the ratio of males to females was 1.54:1 (43/28). In the ICA occlusion group (46 patients), the average age was $62.04 \pm 9.361$ years (range, $41-80$ years), and the ratio of males to females was 1.54:1 (30/16). The age and sex data, and their comparisons are summarized in Tables I-III.

It should be noted that for the participants, their weight, height and body mass index should be included. However, as some data were from the out-patient department, these data could not be provided.

Measured parameters. Among the healthy subjects, the ECA diameter at the OA origin was 4.37 $\pm 0.93 \mathrm{~mm}$ (range, 2.5-8.7 mm). The OA diameter at its origin was $1.94 \pm 0.33 \mathrm{~mm}$ (range, 1.3-2.8 mm). The length of the OA from its origin to the superior nuchal line was $142.2 \pm 19.39 \mathrm{~mm}$ (range, 104.9-185.9 mm). The OA diameter at the superior nuchal line was $1.68 \pm 0.35 \mathrm{~mm}$ (range, 0.8-3.0 mm). The OA diameter $2 \mathrm{~cm}$ above the superior nuchal line was $1.14 \pm 0.39 \mathrm{~mm}$ (range, $0.4-2.3 \mathrm{~mm}$ ). The length of the OA between the superior nuchal line and $2 \mathrm{~cm}$ above the superior nuchal line was 39.34 $\pm 9.1 \mathrm{~mm}$ (range, 22.6-71.2 mm). The OA diameter at the midline of the foramen magnum was 
Table IV. Measured parameters in the different groups.

\begin{tabular}{|c|c|c|c|c|c|}
\hline No. & Parameter & Groups & Range (mm) & Mean $(\mathrm{mm})$ & P-value ${ }^{a}$ \\
\hline \multirow[t]{4}{*}{1} & \multirow[t]{4}{*}{ ECA diameter at the OA origin } & Control & $2.5-8.7$ & $4.37 \pm 0.93$ & \multirow[t]{4}{*}{0.0888} \\
\hline & & Mild and moderate stenosis & $3.0-5.9$ & $4.14 \pm 0.61$ & \\
\hline & & Severe stenosis & $2.9-5.7$ & $4.09 \pm 0.66$ & \\
\hline & & Occlusion & $2.1-6$ & $4.3 \pm 0.86$ & \\
\hline \multirow[t]{4}{*}{2} & \multirow[t]{4}{*}{ OA diameter at its origin } & Control & $1.3-2.8$ & $1.94 \pm 0.33$ & \multirow[t]{4}{*}{0.1260} \\
\hline & & Mild and moderate stenosis & $1.3-2.5$ & $1.89 \pm 0.26$ & \\
\hline & & Severe stenosis & $0.8-2.8$ & $2.02 \pm 0.34$ & \\
\hline & & Occlusion & $1.4-3.1$ & $2.0 \pm 0.31$ & \\
\hline \multirow[t]{4}{*}{3} & \multirow{4}{*}{$\begin{array}{l}\text { Length of the OA from its origin } \\
\text { to the superior nuchal line }\end{array}$} & Control & 104.9-185.9 & $142.2 \pm 19.39$ & \multirow[t]{4}{*}{0.1467} \\
\hline & & Mild and moderate stenosis & $97-211.1$ & $147.1 \pm 22.3$ & \\
\hline & & Severe stenosis & 89.8-198.6 & $143.1 \pm 22.15$ & \\
\hline & & Occlusion & $109.1-200.3$ & $149.6 \pm 19.92$ & \\
\hline \multirow[t]{4}{*}{4} & \multirow{4}{*}{$\begin{array}{l}\text { OA diameter at the superior nuchal } \\
\text { line }\end{array}$} & Control & $0.8-3$ & $1.68 \pm 0.35$ & \multirow[t]{4}{*}{0.5392} \\
\hline & & Mild and moderate stenosis & $0.7-2.3$ & $1.59 \pm 0.39$ & \\
\hline & & Severe stenosis & $0.7-2.7$ & $1.63 \pm 0.45$ & \\
\hline & & Occlusion & $0.9-2.7$ & $1.68 \pm 0.41$ & \\
\hline \multirow[t]{4}{*}{5} & \multirow{4}{*}{$\begin{array}{l}\text { OA diameter } 2 \mathrm{~cm} \text { above the } \\
\text { superior nuchal line }\end{array}$} & Control & $0.4-2.3$ & $1.14 \pm 0.39$ & \multirow[t]{4}{*}{0.6269} \\
\hline & & Mild and moderate stenosis & $0.4-2.2$ & $1.07 \pm 0.45$ & \\
\hline & & Severe stenosis & $0.4-2.0$ & $1.08 \pm 0.38$ & \\
\hline & & Occlusion & $0.5-2.2$ & $1.06 \pm 0.39$ & \\
\hline \multirow[t]{4}{*}{6} & \multirow{4}{*}{$\begin{array}{l}\text { Length of the OA between the } \\
\text { superior nuchal line and } 2 \mathrm{~cm} \\
\text { above the superior nuchal line }\end{array}$} & Control & $22.6-71.2$ & $39.34 \pm 9.10$ & \multirow[t]{4}{*}{0.0782} \\
\hline & & Mild and moderate stenosis & $23.9-64.1$ & $36.71 \pm 7.74$ & \\
\hline & & Severe stenosis & 20.4-61.1 & $36.25 \pm 8.55$ & \\
\hline & & Occlusion & $22.4-59.1$ & $36.83 \pm 7.93$ & \\
\hline \multirow[t]{4}{*}{7} & \multirow{4}{*}{$\begin{array}{l}\text { OA diameter at the midline of the } \\
\text { foramen magnum }\end{array}$} & Control & $1.5-3.1$ & $2.07 \pm 0.39$ & \multirow[t]{4}{*}{0.3562} \\
\hline & & Mild and moderate stenosis & $1.5-2.8$ & $1.97 \pm 0.24$ & \\
\hline & & Severe stenosis & $1.4-3.4$ & $2.04 \pm 0.37$ & \\
\hline & & Occlusion & $1.4-2.8$ & $2.08 \pm 0.36$ & \\
\hline \multirow[t]{4}{*}{8} & \multirow{4}{*}{$\begin{array}{l}\text { Distance from the edge of the } \\
\text { foramen magnum to the OA }\end{array}$} & Control & $24.1-42.1$ & $29.88 \pm 3.47$ & \multirow[t]{4}{*}{0.8757} \\
\hline & & Mild and moderate stenosis & $24.6-38.4$ & $29.54 \pm 3.20$ & \\
\hline & & Severe stenosis & $24.3-36.2$ & $29.72 \pm 2.64$ & \\
\hline & & Occlusion & $23.2-35.9$ & $29.49 \pm 2.98$ & \\
\hline \multirow[t]{4}{*}{9} & \multirow{4}{*}{$\begin{array}{l}\text { Length of the OA from the midline } \\
\text { level of the foramen magnum to the } \\
\text { superior nuchal line }\end{array}$} & Control & $56.9-129.5$ & $89.82 \pm 14.89$ & 0.8427 \\
\hline & & Mild and moderate stenosis & $54.9-129.9$ & $92.25 \pm 15.56$ & \\
\hline & & Severe stenosis & $41.3-153.5$ & $91.08 \pm 19.36$ & \\
\hline & & Occlusion & 51.4-136.7 & $91.44 \pm 15.33$ & \\
\hline 10 & Distance from the midline to the & Control & $25.6-48.7$ & $36.09 \pm 4.42$ & 0.0723 \\
\hline & OA at the level of the superior & Mild and moderate stenosis & $27.7-45.2$ & $35.96 \pm 4.16$ & \\
\hline & nuchal line & Severe stenosis & $19.3-48.3$ & $37.75 \pm 5.15$ & \\
\hline & & Occlusion & $26.1-45.5$ & $36.34 \pm 4.72$ & \\
\hline
\end{tabular}

In the table, the control group included 100 sides (left and/or right), the mild and moderate ICA stenosis group included 50 sides (left and/or right), the severe ICA stenosis group included 80 sides (left and/or right), and the ICA occlusion group included 50 sides (left and/or right). ${ }^{a}$ The data were analyzed using ordinary one-way ANOVA; due to the P-value $>0.05$, one-way ANOVA indicated that the degree of ICA stenosis had no significant effect on these parameters. The P-values from multiple comparisons between groups are presented in Table V. CA, external carotid artery; ICA, internal carotid artery; OA, occipital artery.

$2.07 \pm 0.39 \mathrm{~mm}$ (range, $1.5-3.1 \mathrm{~mm}$ ). The distance from the edge of the foramen magnum to the OA was $29.88 \pm 3.47 \mathrm{~mm}$ (range, 24.1-42.1 mm). The length of the OA from the midline level of the foramen magnum to the superior nuchal line was
89.82 $\pm 14.89 \mathrm{~mm}$ (range, 56.9-129.5 $\mathrm{mm}$ ). The distance from the midline to the OA at the level of the superior nuchal line was $36.09 \pm 4.42 \mathrm{~mm}$ (range, 25.6-48.7 $\mathrm{mm}$ ). The overall data and their comparisons are summarized in detail in Tables IV and V. 


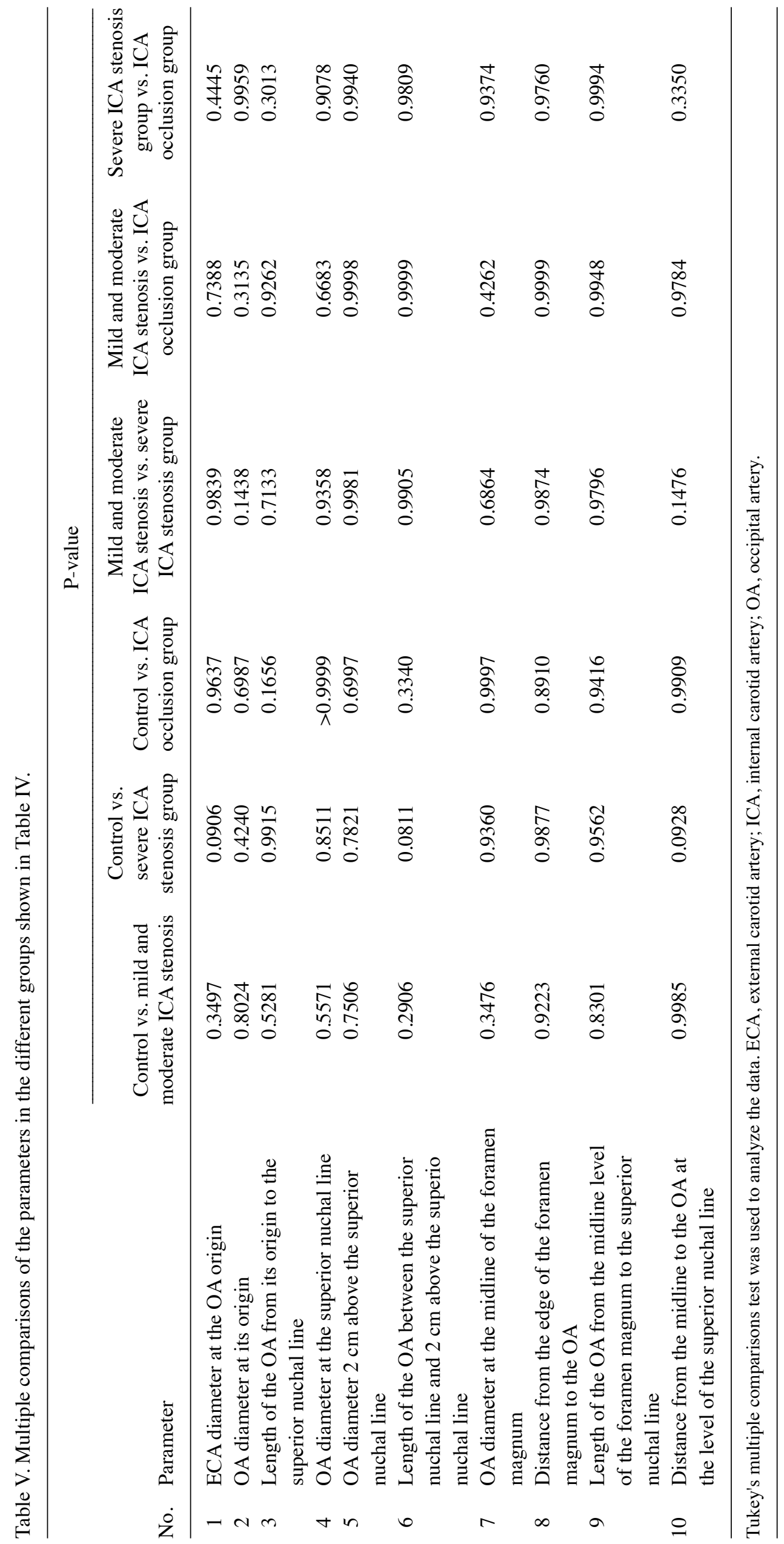


Table VI. Measured parameters in the control group.

\begin{tabular}{|c|c|c|c|c|c|}
\hline No. & Parameter & Side & Range (mm) & Mean (mm) & P-value \\
\hline \multirow[t]{2}{*}{1} & \multirow[t]{2}{*}{ ECA diameter at the OA origin } & $\mathrm{L}$ & $2.8-8.7$ & $4.35 \pm 0.97$ & \multirow[t]{2}{*}{0.8079} \\
\hline & & $\mathrm{R}$ & $2.5-7.4$ & $4.38 \pm 0.89$ & \\
\hline \multirow[t]{2}{*}{2} & \multirow[t]{2}{*}{ OA diameter at its origin } & $\mathrm{L}$ & $1.4-2.8$ & $1.93 \pm 0.34$ & \multirow[t]{2}{*}{0.5843} \\
\hline & & $\mathrm{R}$ & $1.3-2.6$ & $1.95 \pm 0.32$ & \\
\hline \multirow[t]{2}{*}{3} & \multirow[t]{2}{*}{ Length of the OA from its origin to the superior nuchal line } & $\mathrm{L}$ & $106.9-185.9$ & $143.6 \pm 18.06$ & \multirow[t]{2}{*}{0.3137} \\
\hline & & $\mathrm{R}$ & $104.9-178.5$ & $140.8 \pm 20.73$ & \\
\hline \multirow[t]{2}{*}{4} & \multirow[t]{2}{*}{ OA diameter at the superior nuchal line } & $\mathrm{L}$ & $0.8-3.0$ & $1.69 \pm 0.37$ & \multirow[t]{2}{*}{0.7572} \\
\hline & & $\mathrm{R}$ & $0.9-2.5$ & $1.67 \pm 0.33$ & \\
\hline \multirow[t]{2}{*}{5} & \multirow[t]{2}{*}{ OA diameter $2 \mathrm{~cm}$ above the superior nuchal line } & $\mathrm{L}$ & $0.5-2.3$ & $1.16 \pm 0.38$ & \multirow[t]{2}{*}{0.3075} \\
\hline & & $\mathrm{R}$ & $0.4-2.2$ & $1.12 \pm 0.40$ & \\
\hline \multirow[t]{2}{*}{6} & Length of the OA between the superior nuchal line and & $\mathrm{L}$ & $22.6-64.4$ & $40.09 \pm 9.32$ & \multirow[t]{2}{*}{0.4840} \\
\hline & $2 \mathrm{~cm}$ above the superior nuchal line & $\mathrm{R}$ & $22.8-71.2$ & $38.62 \pm 8.91$ & \\
\hline \multirow[t]{2}{*}{7} & \multirow[t]{2}{*}{ OA diameter at the midline of the foramen magnum } & $\mathrm{L}$ & $1.5-3.0$ & $2.06 \pm 0.38$ & \multirow[t]{2}{*}{0.8261} \\
\hline & & $\mathrm{R}$ & $1.6-3.1$ & $2.08 \pm 0.40$ & \\
\hline \multirow[t]{2}{*}{8} & \multirow[t]{2}{*}{ Distance from the edge of the foramen magnum to the OA } & $\mathrm{L}$ & $24.1-42.1$ & $30.29 \pm 3.69$ & \multirow[t]{2}{*}{0.1594} \\
\hline & & $\mathrm{R}$ & $24.7-40.0$ & $29.46 \pm 3.22$ & \\
\hline \multirow[t]{2}{*}{9} & \multirow{2}{*}{$\begin{array}{l}\text { Length of the OA from the midline level of the foramen } \\
\text { magnum to the superior nuchal line }\end{array}$} & $\mathrm{L}$ & $56.9-126.5$ & $89.28 \pm 16.21$ & \multirow[t]{2}{*}{0.5473} \\
\hline & & $\mathrm{R}$ & $65.0-129.5$ & $90.36 \pm 13.59$ & \\
\hline \multirow[t]{2}{*}{10} & \multirow{2}{*}{$\begin{array}{l}\text { Distance from the midline to the OA at the level of the } \\
\text { superior nuchal line }\end{array}$} & $\mathrm{L}$ & $27.6-47$ & $36.78 \pm 4.24$ & \multirow[t]{2}{*}{0.0957} \\
\hline & & $\mathrm{R}$ & $25.6-48.7$ & $35.44 \pm 4.54$ & \\
\hline
\end{tabular}

In the table, the control group included 100 sides (50 left sides and right sides). Data were analyzed using a paired t-test. L, left; R, right; ECA, external carotid artery; ICA, internal carotid artery; OA, occipital artery.

$O A$ variations. A common origin of the $\mathrm{OA}$ and the ascending pharyngeal artery was found on $15.4 \%$ of sides (43/280). A common origin of the $\mathrm{OA}$ and the posterior auricular artery was observed on $3.6 \%$ of sides (10/280). The OA-vertebral artery was found in $2.1 \%$ of sides $(6 / 280)$. The OA arising from the ICA was not observed.

Results of the statistical analysis. There were no significant differences in age, sex, or anatomical parameters of the OA among the control, mild and moderate ICA stenosis group, severe ICA stenosis group and ICA occlusion groups $(\mathrm{P}>0.05)$ (Tables I-V). In the control group, no significant difference in anatomical parameters between the left and right sides was observed (Table VI).

\section{Discussion}

The OA is a crucial structure (1), and is often be used as a donor graft for cerebral revascularization (15). This vessel may also be involved in high-flow arteriovenous shunts, functioning as an accomplice, such as in cases of DAVF where the OA is dilated and hyperplastic (Fig. 4) (1). In cases of stenosis and occlusion of the ICA, the blood flow through the ECA is entirely from the common carotid artery (16). In these cases, it is unclear whether the OA becomes thicker or longer. If the OA becomes thicker or longer, performing a bypass between the suboccipital segment of the OA and intracranial artery may help treat brain hypoperfusion.
In the present study, CTA data were collected from a control group with a normal ICA and patients with stenosis and occlusion of the ICA. The analysis of the OA diameter did not reveal any differences among the different locations and OA lengths among all groups, indicating that the redistribution of blood flow due to severe stenosis or occlusion of the ICA was insufficient in changing the anatomic characteristics of the OA. In addition, these OA data are valuable, as there are no previous studies that have provided CTA data on the OA in Han Chinese population, at least to the best of our knowledge.

The OA is a large artery that has been reported to provide a mean blood flow of 15 to $80 \mathrm{ml} / \mathrm{min}$ when used for posterior fossa bypass (17). In a previous microanatomical study by Alvernia et al (18), the outer diameter of the OA at the origin varied from 2.2-2.9 $\mathrm{mm}$.

In the present study, in healthy subjects, the OA diameter at its origin was $1.94 \mathrm{~mm}$, which is smaller than that in the study by Alvernia et al (18); this may be due to the fact that the OA diameter in the present study was the inner diameter. Additionally, in the present study, in healthy subjects, the ECA diameter at the OA origin was measured to be $4.37 \mathrm{~mm}$, which is much larger than that of the OA. An inner diameter of $1.94 \mathrm{~mm}$ is sufficient for endovascular treatment through the OA, easily allowing double $0.017^{\prime}$ microcatheters to pass through (19).

The OA branches from the ECA; in rare cases, the OA can arise from the ICA (20). In the present study, the latter was not found, perhaps due to the small sample size. However, 

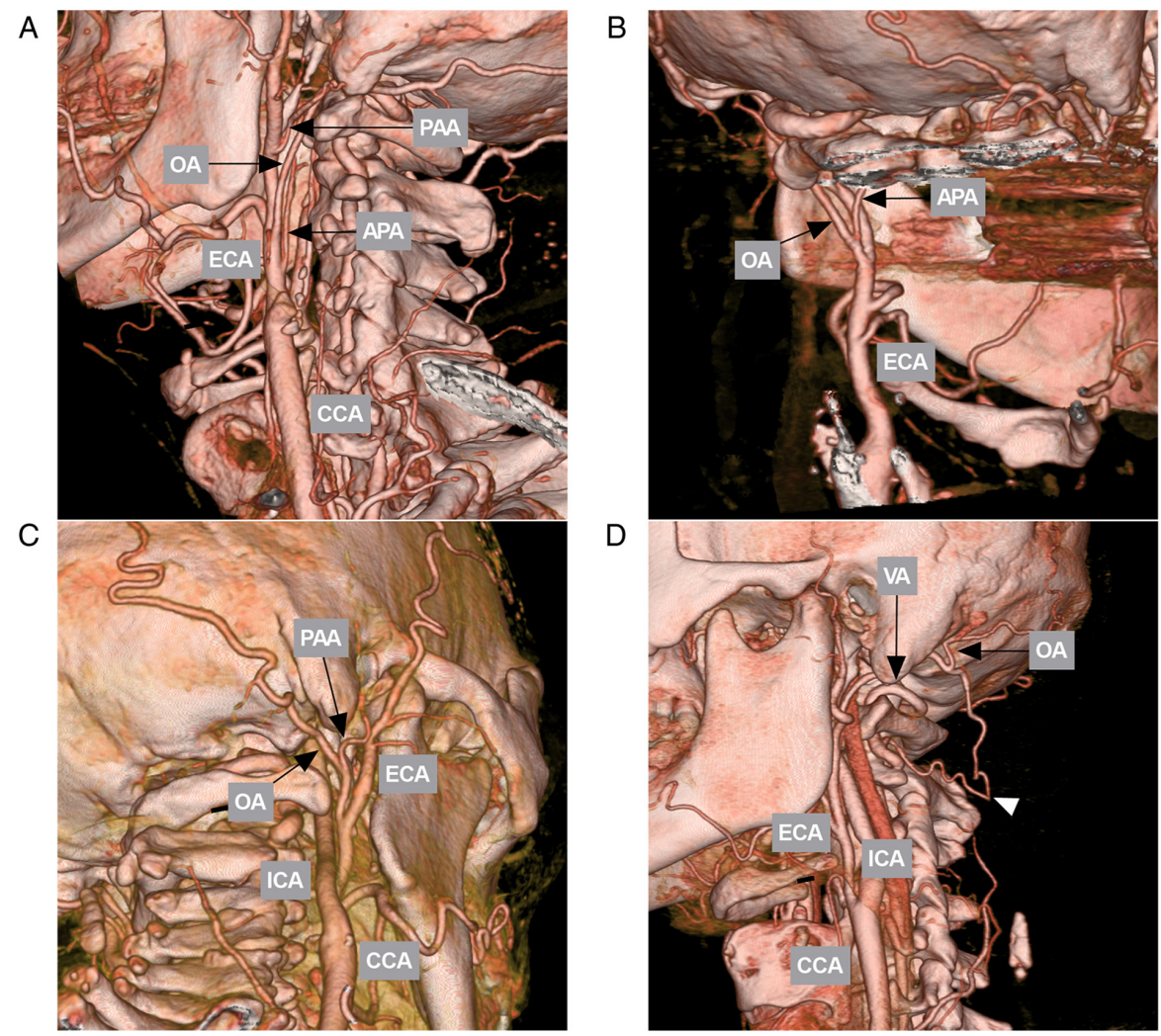

Figure 3. OA variations on CTA. (A) CTA illustrating the normal order of the APA, OA and PAA. (B) CTA illustrating the common trunk of the OA and APA. (C) CTA illustrating the common trunk of the OA and PAA. (D) CTA illustrating the anastomosis of the OA and VA (arrowhead). CCA, common carotid artery; CTA, computed tomography angiography; ECA, external carotid artery; ICA, internal carotid artery; OA, occipital artery; VA, vertebral artery; APA, ascending pharyngeal artery; PAA, posterior auricular artery.

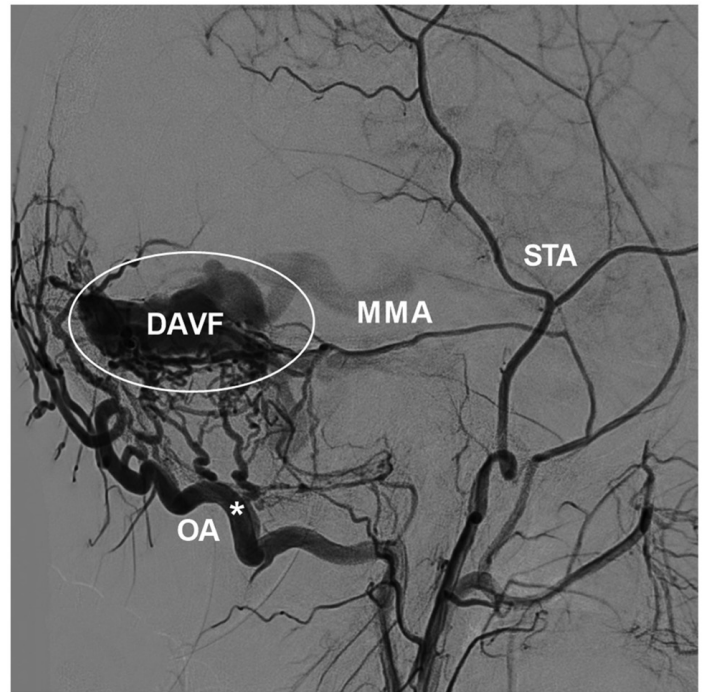

Figure 4. Dilated OA in DAVF as a feeding artery. Lateral digital subtracted angiography of the external carotid artery illustrating that the OA (asterisk) was dilated and was the feeding artery of a DAVF (circle); the MMA also served as a feeding artery. The image presented was from a case with DAVF that was not included in the present study. Patient consent for publication and written informed consent were acquired. DAVF, dural arteriovenous fistula; MMA, middle meningeal artery; OA, occipital artery; STA, superficial temporal artery.

a common trunk of the OA with other branches of the ECA or OA anastomosis with the vertebral artery were found; a common origin with the ascending pharyngeal artery was observed in $15.4 \%$ of sides, and a common origin with the posterior auricular artery in $3.6 \%$ of sides. In the study by Hayashi et al (21), the incidence of the origin of the ascending pharyngeal artery from the OA was $19 \%$, which was similar to that presented herein. These variations are important; for instance, during endovascular treatment via the OA, care must be taken to avoid damaging the ascending pharyngeal artery and posterior auricular artery. The OA-vertebral artery anastomosis was in $2.1 \%$ of sides in the present study. Anastomosis is important, and when the ICA or vertebral artery is occluded, the OA can serve as an important path of collateral circulation.

After leaving the ECA, the OA then runs in the occipital groove of the temporal bone, medial to the digastric groove (Fig. 5) (22). The digastric groove is an important landmark; a number of studies have measured the diameter of the OA at the level of the digastric groove. For instance, in a previous microanatomical study by Matsuo et al (3), the diameter of the $\mathrm{OA}$ at the level of the digastric groove was $2.1 \mathrm{~mm}$. In another microanatomical study by Kawashima et al (23), the diameter of the OA was $2.05 \mathrm{~mm}$ at its exit from the digastric groove. The present study measured the OA diameter at the midline of the foramen magnum, which corresponds to the digastric groove; the diameter in healthy subjects was $2.07 \mathrm{~mm}$; thus the results of the present study were similar to those of the previous aforementioned studies. Furthermore, the distance from the edge of the foramen magnum to the OA was measured, which was $29.88 \mathrm{~mm}$, providing the spatial position of the OA at the level.

For a bypass between the OA and intracranial artery, the OA should be dissected from its distal end, and the dissection should extend to the level of the mastoid process after 

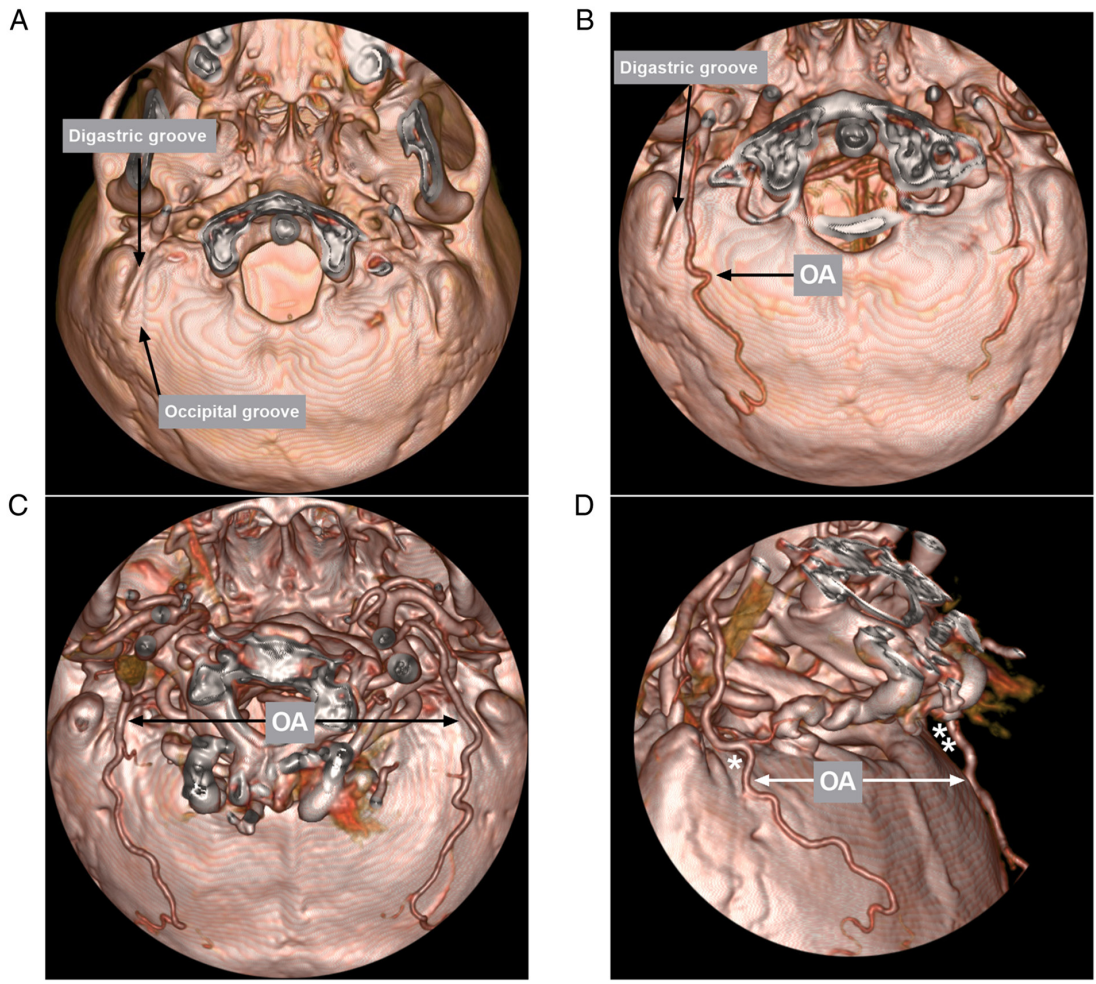

Figure 5. Computed tomography angiography of the course of the OA in the occipital groove. (A and B) The images presented were from the same case. The digastric groove and occipital groove are shown; (B) the OA runs in the occipital groove. (C and D) The images presented were from the same case. The bilateral OAs are shown; (D) the right OA (single asterisk) was close to the occipital groove and the left OA (double asterisks) was away from the occipital groove. OA, occipital artery.

the digastric groove (4). In a previous microsurgical study by Kawashima et al (23), the mean length of the OA from the exit of the digastric groove to the level of the superior nuchal line was $81.9 \mathrm{~mm}$. In the present study, the length in the healthy subjects was $89.82 \mathrm{~mm}$. This difference may be derived from the fact that the study by Kawashima et al (23) was a microsurgical study, and the dissection could not reach the digastric groove; however, the present study used CTA, avoiding muscle disturbances. Nossek et al (24) recommend that a total length of $10-12 \mathrm{~cm}$ be dissected to reach the anastomosis site to avoid any tension in the region of the anastomotic sutures. In the present study, the length of the OA between the superior nuchal line and $2 \mathrm{~cm}$ above the superior nuchal line in healthy subjects was $39.34 \mathrm{~mm}$, and the total length from the digastric groove was $12.92 \mathrm{~cm}$ (89.82 plus $39.34 \mathrm{~mm})$, which was a sufficient length.

The OA crossed upwards over the superior nuchal line; however, its diameter did not decrease significantly at this point. In the study by Kawashima et al (23), the mean diameter of the OA was $2.01 \mathrm{~mm}$ at the level of the superior nuchal line. In the present study, this value in healthy subjects was $1.68 \mathrm{~mm}$, which is smaller than that in the aforementioned study. The reason for this difference may be that the parameter measured for the peripheral OA on CTA was the inner diameter, which is expected to be smaller than the values obtained in microanatomical studies. In addition, due to the poor filling of peripheral vessels, the measured parameters were not accurate (25).

For surgical purposes, it is important to consider that the diameter of the main trunk of the OA remains $>1.0 \mathrm{~mm}$. In the study by Alvernia et al (18), the diameter of the OA was still $>1.0 \mathrm{~mm}$ at $50 \mathrm{~mm}$ above the superior nuchal line. In the present study, ot was found that this measurement became inaccurate $20 \mathrm{~mm}$ above the superior nuchal line o CTA; thus, the OA diameter at this point was measured only in healthy subjects and a value of $1.14 \mathrm{~mm}$ was obtained. For an OA bypass, an accurate understanding of the orientation is crucial, and previous studies have demonstrated that the OA travels $3.0-4.5 \mathrm{~cm}$ on the superior nuchal line lateral to the inion $(3,4)$. In the present study, this parameter in healthy subjects was measured to be $36.09 \mathrm{~mm}$, in agreement with the aforementioned studies $(3,4)$.

In conclusion, the presents study reported data on the OA diameter in Han Chinese patients. In addition, it was demonstrated that the stenosis and occlusion of the ICA did not significantly alter the anatomy of the OA.

\section{Acknowledgements}

Not applicable.

\section{Funding}

No funding was received.

\section{Availability of data and materials}

The datasets used and/or analyzed during the current study are available from the corresponding author on reasonable request.

\section{Authors' contributions}

JY designed the study and drafted the manuscript. TL collected the data. TL and JY confirm the authenticity of all 
the raw data. JY and TL revised the manuscript. Both authors have read and approved the final manuscript.

\section{Ethics approval and consent to participate}

The present study was approved by the Ethics Committee of the First Hospital of Jilin University (Approval no. 2021-533). Written informed consent was obtained from the participants.

\section{Patient consent for publication}

The participants or their parents/guardians provided consent and agreed to have their data (shown in the figures) published.

\section{Competing interests}

The authors declare that they have no competing interests.

\section{References}

1. Guo Y, Chen H, Chen X and Yu J: Clinical importance of the occipital artery in vascular lesions: A review of the literature. Neuroradiol J 32: 366-375, 2019.

2. Guo Y, Song Y, Hou K and Yu J: Intracranial fusiform and circumferential aneurysms of the main trunk: Therapeutic dilemmas and prospects. Front Neurol 12: 679134, 2021.

3. Matsuo S, Komune N, Akiyama O, Amano T and Nakamizo A: Surgical anatomy of the donor arteries for extracranial-intracranial bypass surgery: An anatomic and radiologic study. World Neurosurg 136: e447-e459, 2020.

4. Ateş O, Ahmed AS, Niemann D and Başkaya MK: The occipital artery for posterior circulation bypass: Microsurgical anatomy. Neurosurg Focus 24: E9, 2008.

5. Lasjaunias P, Théron $\mathbf{J}$ and Moret $\mathrm{J}$ : The occipital artery. Anatomy-normal arteriographic aspects-embryological significance. Neuroradiology 15: 31-37, 1978.

6. Hou K, Li Q, Xu K, Xu B and Yu J: Anatomical features of the superficial temporal artery in hemorrhagic moyamoya disease based on CT angiography. Exp Ther Med 19: 2143-2148, 2020

7. Ji T, Hou K, $\mathrm{Li} \mathrm{C}$ and $\mathrm{Yu} \mathrm{J}$ : Imaging features of internal maxillary artery and extracranial middle meningeal artery and their relationships on head CTA. Neuroradiol J 34: 629-641, 2021.

8. Chen Y, Xue HD, Liu W, Sun H, Wang X, Su BY, Duo C, Ming WD, De J, Ji B, et al: Dual-energy computed tomographic angiography of head and neck arteries with different contrast material doses in second generation dual-source computed tomography system. Zhongguo Yi Xue Ke Xue Yuan Xue Bao 32: 628-633, 2010 (In Chinese).

9. Chen G, Xue Y, Wei J and Duan Q: The undiagnosed potential clinically significant incidental findings of neck CTA: A large retrospective single-center study. Medicine (Baltimore) 99: e22440, 2020.

10. Chen H, Xu B, Wang G, Guo Y, Hou K and Yu J: Posterior occipital intramuscular hemangioma mimicking arteriovenous malformation: Case report. Medicine (Baltimore) 98: e14678, 2019.
11. Yuan Y, Xu B, Guo Y, Xu K, Luo Q and Yu J: Surgical excision of large scalp hemangiomatosis: A case report and literature review. Int J Clin Exp Me 9: 6853-6861, 2016.

12. Oishi H, Yoshida K, Tange Y, Tsuji O and Sonobe M: Treatment of a scalp arteriovenous malformation by a combination of embolization and surgical removal. Interv Neuroradiol 8: 293-297, 2002.

13. Su H, Xu K, Wang Y and Yu J: Is the middle meningeal artery the optimal path for dural arteriovenous fistula embolization? Front Neurol 12: 675355, 2021.

14. Barnett HJ, Taylor DW, Eliasziw M, Fox AJ, Ferguson GG, Haynes RB, Rankin RN, Clagett GP, Hachinski VC, Sackett DL, et al: Benefit of carotid endarterectomy in patients with symptomatic moderate or severe stenosis. North American symptomatic carotid endarterectomy trial collaborators. N Engl J Med 339: 1415-1425, 1998.

15. Verbraeken B, Aboukais R, Voormolen M, Boogaarts HD, Leclerc X, Lejeune JP and Menovsky T: Extreme lateral supracerebellar infratentorial approach (ELSCIT) for occipital artery-to-posterior cerebral artery bypass: Results in 3 cases. World Neurosurg 152: 214-220, 2021.

16. Xu B, Li C, Guo Y, Xu K, Yang Y and Yu J: Current understanding of chronic total occlusion of the internal carotid artery. Biomed Rep 8: 117-125, 2018.

17. Khodadad G: Short- and long-term results of microvascular anastomosis in the vertebrobasilar system, a critical analysis. Neurol Res 3: 33-65, 1981.

18. Alvernia JE, Fraser K and Lanzino G: The occipital artery: A microanatomical study. Neurosurgery 58 (Suppl 1): ONS114-ONS122, 2006.

19. Kelly ME, Gonugunta V, Woo HH, Turner R IV and Fiorella D: Double-balloon trapping technique for embolization of a large wide-necked superior cerebellar artery aneurysm: Case report. Neurosurgery 63 (Suppl 2): S291-S292, 2008.

20. Demirbas AT, Demirtas I, Sonmez Topcu F, Karasu S and Ayyildiz B: A rare case report: Bilateral occipital artery arising from the vertebral artery. Surg Radiol Anat 43: 1901-1904, 2021.

21. Hayashi N, Hori E, Ohtani Y, Ohtani O, Kuwayama N and Endo S: Surgical anatomy of the cervical carotid artery for carotid endarterectomy. Neurol Med Chir (Tokyo) 45: 25-30, 2005.

22. Benet A, Tabani H, Ding X, Burkhardt JK, Rodriguez Rubio R, Tayebi Meybodi A, Nisson P, Kola O, Gandhi S, Yousef S and Lawton MT: The transperiosteal 'inside-out' occipital artery harvesting technique. J Neurosurg 130: 207-212, 2018.

23. Kawashima M, Rhoton AL Jr, Tanriover N, Ulm AJ, Yasuda A and Fujii K: Microsurgical anatomy of cerebral revascularization. Part II: Posterior circulation. J Neurosurg 102: 132-147, 2005.

24. Nossek E, Chalif DJ and Dehdashti AR: How I do it: Occipital artery to posterior inferior cerebellar artery bypass. Acta Neurochir (Wien) 156: 971-975, 2014.

25. Naito H, Naka H, Kobayashi M, Kanaya Y, Naito K, Kurashige T, Tokinobu $\mathrm{H}$ and Matsumoto M: Prevalences of peripheral arterial disease diagnosed by computed tomography angiography in patients with acute ischemic stroke. J Stroke Cerebrovasc Dis 25: 1128-1134, 2016. International (CC BY-NC-ND 4.0) License. 